\title{
Occupancy and abundance of large macaws in the Beni savannahs, Bolivia
}

\author{
Igor Berkunsky, Rosana E. Ceppeda, Claudia Marinelli, M. Verónica Simoy \\ Gonzalo Daniele, Federico P. Kacoliris, José A. Díaz Luque \\ Facundo Gandoy, Rosana M. Aramburú and James D. Gilardi
}

\begin{abstract}
Monitoring of wild populations is central to species conservation and can pose a number of challenges. To identify trends in populations of parrots, monitoring programmes that explicitly take detectability into account are needed. We assessed an occupancy model that explicitly accounted for detectability as a tool for monitoring the large macaws of Bolivia's Beni savannahs: the blue-throated Ara glaucogularis, blue-and-yellow Ara ararauna and red-andgreen macaws Ara chloropterus. We also evaluated the joint presence of the three macaw species and estimated their abundance in occupied areas. We modelled occupancy and detection for the three macaw species by combining several site and visit covariates and we described their conditional occupancy. Macaws occupied two thirds of the surveyed area and at least two species occurred together in one third of this area. Probability of detection was $0.48-0.86$. For each macaw species, occupancy was affected by the abundance of the other two species, the richness of cavity-nesting species, and the distance to the nearest village. We identified key priority areas for the conservation of these macaws. The flexibility of occupancy methods provides an efficient tool for monitoring macaw occupancy at the landscape level, facilitating prediction of the range of macaw species at a large number of sites, with relatively little effort. This technique could be used in other regions in which the monitoring of threatened parrot populations requires innovative approaches.
\end{abstract}

Keywords Ara ararauna, Ara chloropterus, Ara glaucogularis, Bolivia, conservation, macaw, occupancy

Igor Berkunsky (Corresponding author), Rosana E. CePeda, Claudia MARINELli and M. VERÓNICA SIMOY Instituto Multidisciplinario sobre Ecosistemas y Desarrollo Sustentable, Universidad Nacional del Centro de la Provincia de Buenos Aires. Campus Universitario, Paraje Arroyo Seco (B7000GHG) Tandil, Argentina. E-mail igorberkunsky@gmail.com

Gonzalo Daniele, Federico P. Kacoliris, Facundo Gandoy and Rosana M. ARAmburú Facultad de Ciencias Naturales y Museo, Universidad Nacional de la Plata, La Plata, Argentina

José A. Díaz Luque and James D. Gilardi Blue-throated Macaw Conservation Project, World Parrot Trust, Trinidad, Bolivia

Received 15 November 2013. Revision requested 27 January 2014.

Accepted 18 March 2014. First published online 17 July 2014.

\section{Introduction}

$\mathrm{M}$ acaws are among the largest and most threatened parrots (BirdLife International, 2013) and populations are in decline as a result of illegal trapping and habitat loss (Snyder et al., 2000). Many of the 16 species of macaws require large tracts of relatively pristine habitat for their survival (Forshaw, 1989). Macaws are adversely affected by anthropogenic activities such as establishment and expansion of roads, towns and cities, collection for the pet trade, hunting, and clearing, alteration and degradation of habitat (Gonzalez, 2003).

Three species of macaws coexist in the Beni savannahs of Bolivia: the blue-throated Ara glaucogularis, blue-andyellow Ara ararauna and red-and-green Ara chloropterus macaws (Hanagarth \& Beck, 1996; Yamashita \& de Barros, 1997). All three have experienced population declines in the Beni savannahs since the 1960 s as a result of local hunting for feathers, poaching for the pet trade, and habitat loss (Ingels et al., 1981; Boussekey et al., 1997; Hesse \& Duffield, 2000).

Rediscovered in the wild in 1992 (Jordan \& Munn, 1993), the blue-throated macaw has undergone a significant population decline and is reported to be the rarest of the macaws in the wild (Hesse \& Duffield, 2000). The estimated population of this Critically Endangered Bolivian endemic is 115 individuals (BirdLife International, 2013). Since 1997 governmental and non-governmental organizations have been working to increase the wild population of the species (Duffield \& Hesse, 1997; Hesse \& Duffield, 2000; Herrera et al., 2007; Berkunsky, 2008, 2010). Each organization has its own monitoring scheme that usually includes annual surveys of sites where the species' presence was confirmed previously, and surveys of new areas in search of new populations.

The blue-and-yellow and red-and-green macaws are two of the most striking Neotropical parrots and are well known in the pet trade (Gonzalez, 2003; Brightsmith \& Bravo, 2006). Both are categorized as Least Concern on the IUCN Red List (BirdLife International, 2013) but local populations have been reduced in parts of their range, especially in areas near human population centres (Forshaw, 1989; Juniper \& Parr, 1998). The blue-and-yellow macaw may be the most resilient of the three species to human activity, whereas the 
red-and-green macaw appears to be the most sensitive (Karubian et al., 2005; Franchin, 2009). Studies have examined multiple aspects of their biology, including activity patterns (Roth, 1984), breeding biology (Brightsmith \& Bravo, 2006; Renton \& Brightsmith, 2009) and habitat use (Karubian et al., 2005; Brightsmith \& Villalobos, 2011). The influence of habitat, season and detectability on abundance has been described for the blue-and-yellow and red-and-green macaws (Lee \& Marsden, 2012). However, no information regarding occupancy and detectability has been recorded for the blue-throated macaw.

As a result of the difficulties in monitoring macaw species, estimates of abundance and occupancy are scarce. Most studies on macaw abundance disregard detectability and observations are usually based on encounter rates, which are dependent on sampling effort, rather than counts based on spatial sampling units (Karubian et al., 2005).

Site occupancy modelling has become increasingly useful to ecologists because species detection or non-detection is determined over multiple sampling occasions, which allows estimates of detection probabilities (MacKenzie et al., 2005; Kroll et al., 2007; Weller, 2008). Site occupancy modelling also provides a flexible framework that facilitates modelling of occupancy as a function of covariate information (MacKenzie et al., 2005; Olea \& Mateo-Tomás, 2011). The use of covariates, such as distance to villages, elevation and human presence, can provide information about the factors influencing habitat use by species (Zeller et al., 2011). Understanding how these variables affect the probabilities of occupancy and detection of the species is critical for the design of efficient monitoring protocols.

Here, we use occupancy models that account explicitly for detectability (MacKenzie et al., 2005), to determine detection probabilities and occupancy of blue-throated, blue-and-yellow and red-and-green macaws in the Beni savannahs. We also investigate the coexistence of the three species. Finally, we discuss how our results could be applied to the on-going monitoring programme for the bluethroated macaw and for monitoring programmes for other macaw species.

\section{Study area}

We conducted surveys in the Beni savannahs (Fig. 1), a $160,000 \mathrm{~km}^{2}$ region of seasonally inundated lowlands occupying the Beni-Mamoré-Iténez basin in south-west Amazonia, Bolivia (Mayle et al., 2007). Mean annual precipitation is $1,300-2,000 \mathrm{~mm}$ across the region, with precipitation occurring mostly during September-May (Hanagarth \& Beck, 1996). The area is inhabited at low densities, with cattle-ranching being the primary economic activity (Mayle et al., 2007).

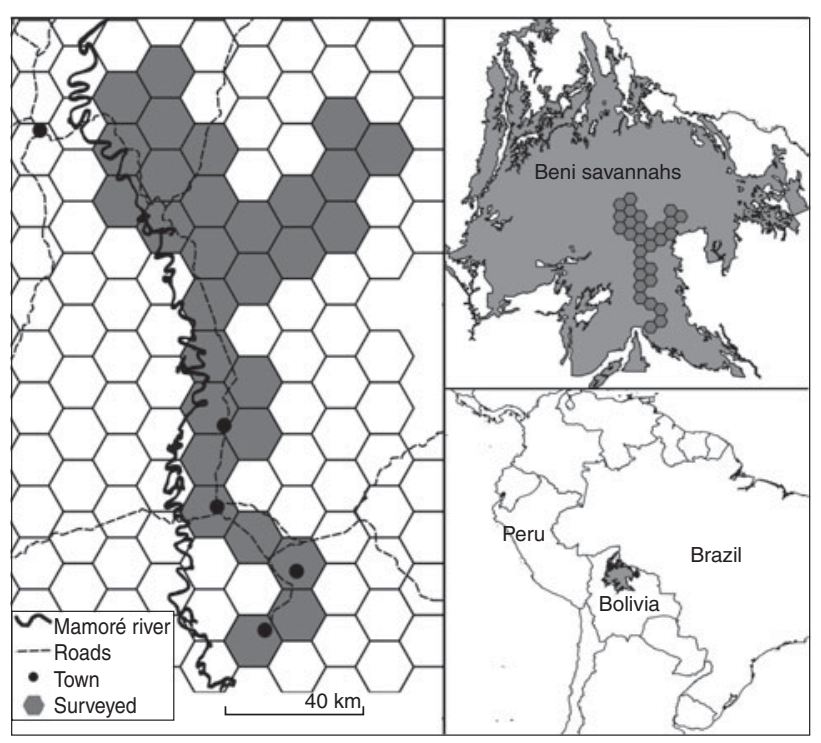

FIG. 1 Location of the 29 sampling hexagons surveyed in the Beni savannahs, in northern Bolivia.

The landscape of the Beni savannahs is dominated by flat, low-lying areas of open, treeless savannah (Mayle et al., 2007). Forest patches are scarce and restricted to areas that are sufficiently high to avoid flooding. Most forest patches are eroded relics of natural levees or terraces of abandoned river channels, which constitute fragments of gallery forest (Hanagarth \& Beck, 1996). The Beni savannahs are poorly represented in Bolivia's protected areas, none of which overlap with our study site. Protected lowlands with little savannah are found at the borders of the ecoregion at the Beni Biological Station, $150 \mathrm{~km}$ from the study area (Beck \& Moraes, 1997).

\section{Methods}

From a randomly selected starting point we generated a hexagonal sampling grid that encompassed a significant proportion of the Beni savannahs region. The area of the hexagon $\left(232.7 \mathrm{~km}^{2}\right)$ was based on the mean recorded home range for breeding pairs of blue-throated macaws (IB, pers. obs.).

We conducted surveys from 8 September to 9 November 2011, at the end of the dry season, to coincide with the peak of the reproductive season of large macaw species in the Beni region (IB, pers. obs.). During the breeding season, breeding pairs remain in the proximity of nesting areas, which facilitates counts.

We surveyed 29 hexagons, covering 6,750 km² (Fig. 1). Access limitations and time constraints prevented us from conducting repeat surveys in seven of the hexagons. Landscape heterogeneity resulted in a variable number of forest patches in each hexagon. Forest patches were surveyed by four trained observers (IB, GD, JADL and FG) during 06.00-10.00 and 14.00-18.00. 
TABLE 1 Variables (with their type and description) surveyed in each sampling hexagon in the Beni savannahs, Bolivia (Fig. 1).

\begin{tabular}{|c|c|c|}
\hline Variable & Type & Description \\
\hline$D$ & Continuous & Distance to the nearest village $(\mathrm{km})$ \\
\hline$R$ & Discrete & $\begin{array}{l}\text { Total number of cavity-nesting } \\
\text { species }\end{array}$ \\
\hline$M_{\mathrm{BTM}}$ & Discrete & $\begin{array}{l}\text { Maximum number of blue-throated } \\
\text { macaws Ara glaucogularis detected }\end{array}$ \\
\hline$M_{\mathrm{BYM}}$ & Discrete & $\begin{array}{l}\text { Maximum number of blue-and- } \\
\text { yellow macaws Ara ararauna } \\
\text { detected }\end{array}$ \\
\hline$M_{\mathrm{RGM}}$ & Discrete & $\begin{array}{l}\text { Maximum number of red-and-green } \\
\text { macaws Ara chloropterus detected }\end{array}$ \\
\hline Ap & Dichotomous & Presence of Attalea phalerata \\
\hline Aa & Dichotomous & Presence of Acrocomia aculeata \\
\hline $\mathrm{Ca}$ & Dichotomous & Presence of Copernicia alba \\
\hline C & Dichotomous & Presence of cattle \\
\hline$H$ & Dichotomous & $\begin{array}{l}\text { Historical occupation by the blue- } \\
\text { throated macaw }\end{array}$ \\
\hline$V$ & Continuous & Duration of visit \\
\hline
\end{tabular}

In each hexagon we selected several variables that could be affecting levels of occupancy of macaws (Table 1). We expected a higher probability of occupancy in hexagons where food and nesting resources were present and threats absent. The presence of other avian species or groups of species has been used as an indicator of habitat condition (Roberge \& Angelstam, 2006). The presence of cavitynesting species is commonly linked to availability of nesting resources (Cornelius et al., 2008). We assumed that hexagons with more nesting resources would support a higher number of cavity-nesting species, and therefore we used the number of medium and large cavity-nesting species as a covariate variable.

Three species of palms (Acrocomia aculeata, Attalea phalerata and Copernicia alba) are commonly used for food and nesting by most local parrot species (Yamashita \& de Barros, 1997). Previous findings have suggested that the blue-throated macaw is associated with both $A$. phalerata and $A$. aculeata, which are sources of food and nesting sites for this species (Boussekey et al., 1997; Yamashita \& de Barros, 1997). The presence of these common species of palm trees in the area was used as a covariate associated with resources.

Cattle ranching, which is the main human activity in the region, is an indirect threat to macaws. People regularly burn the savannah to produce grazing land, and fires destroy trees in forest patches. Hunting pressure also appears to be higher near settlements. Local people explore the surroundings of their villages in search of places to hunt. Presence of cattle and distance to villages (from the centre of the hexagon to the centre of the settlement or village) were therefore used as covariates associated with threats.

Trained observers walked 200-m transects in each forest patch. Transects were allocated following the direction of the major dimension of the patch. In most cases one transect was sufficient to cover the entire patch, and we surveyed a maximum of three transects in large patches. For each hexagon we recorded the detection or non-detection of each target bird and palm species, and direct and indirect evidence (faeces and tracks) of cattle. Visual and vocal detections were recorded for all medium and large cavity nesters of the following families: Cathartidae, Falconidae, Tytonidae, Strigidae, Anatidae, Psittacidae, Trogonidae, Ramphastidae and Picidae. We also recorded the number of blue-throated, blue-and-yellow and red-and-green macaws detected, and recorded the duration of each visit, to account for differences in sampling effort.

The abundance of macaw species should reflect a relationship between the availability of resources and the presence of threats. We expected that hexagons where blueand-yellow and red-and-green macaws were abundant would have a higher probability of occupancy by bluethroated macaws. To model occupancy of the blue-throated macaw we used the sum of the maximum number of detected individuals of blue-and-yellow and red-and-green macaws as a covariate. We applied the same hypothesis for the other two macaw species.

For the blue-throated macaw we defined historical occupation as an additional binary variable for each hexagon. Historical occupation was equal to 1 in hexagons where blue-throated macaws were reported previously (Hesse \& Duffield, 2000; Berkunsky, 2008). A number of studies have monitored the presence of the species (Duffield \& Hesse, 1997; Hesse \& Duffield, 2000; Herrera et al., 2007; Berkunsky, 2008, 2010), and our study area includes the whole known breeding range of the blue-throated macaw.

Occupancy can be defined simply as the proportion of patches in which a species is found (MacKenzie et al., 2005). For each macaw species we estimated both naïve occupancy and detection (i.e. the proportion of visits where a species was detected). As we conducted three surveys in most hexagons (18 of 29) we built detection histories of three visits for each hexagon and each of the three macaw species. There were missing data in the detection histories of 11 hexagons.

We modelled occupancy of each macaw species, using a method that accounts explicitly for detectability, and we used the maximum likelihood approach to estimate occupancy values (MacKenzie et al., 2005). The basis of the model is that there are two stochastic processes occurring that affect whether a species is detected at a site. A site may be either occupied or unoccupied by the species; if it is occupied then at each visit there is some probability of detecting the species.

We evaluated the simplest model for each macaw species, in which both detection and occupancy probabilities were assumed to be constant. We also incorporated site covariates (Table 1) into the model through a logit link function. We evaluated all potential models without interactions and 
considered only models with 2-4 parameters (including the intercept and probability of detection). The number of parameters was limited by the number of detection histories in the data set (MacKenzie et al., 2005). Two parameters were needed to estimate model intercepts (i.e. occupancy and detection); thus, a maximum of two parameters was available to model covariate variables. We used the corrected Akaike information criterion $\left(\mathrm{AIC}_{\mathrm{c}}\right)$ to identify and rank the most parsimonious models. We assessed the fit of our models, using a goodness-of-fit test based on bootstrapping and Pearson's $\chi^{2}$ (MacKenzie \& Bailey, 2004).

For each sampling hexagon we obtained estimates of occupancy $\left(\hat{\Psi}_{i}\right)$. Using those estimations we applied a bootstrap method to calculate an overall estimate of occupancy $(\Psi)$, with a $95 \%$ confidence interval. We computed a conditional probability $\left(\Psi_{i}\right)$, taking detection history into account. For single-state models, $\Psi_{\text {cond }}=1$ for hexagons with at least one detection because species presence was established unambiguously. Finally, we plotted the conditional probability of each hexagon for each species studied. We ran models in PRESENCE v. 3.1 (MacKenzie et al., 2005).

\section{Results}

We recorded macaws in $66 \%$ of the 29 hexagons surveyed. We counted 25 blue-throated macaws in seven hexagons, 156 blue-and-yellow macaws in 17 hexagons, and 33 red-andgreen macaws in 10 hexagons. The naïve occupancy was $24 \%$ for blue-throated, $59 \%$ for blue-and-yellow, and $34 \%$ for redand-green macaws. The naïve probabilities of detection were $0.73 \pm$ SE $0.12(n=5)$ for blue-throated, $0.61 \pm$ SE 0.08 $(\mathrm{n}=13)$ for blue-and-yellow, and $0.47 \pm \operatorname{SE} 0.11(\mathrm{n}=6)$ for red-and-green macaws. The number of individuals detected per visit per sampling hexagon was 2-9 blue-throated, 1-56 blue-and-yellow, and 1-15 red-and-green macaws. We found C. alba in 28 hexagons (97\%), and A. phalerata and A. aculeata in 27 hexagons (93\%). We present continuous covariate variables and their statistical descriptions in Table 2.

The top models for the three macaw species include the maximum number of individuals and cavity-nester richness (Table 3). The positive values in estimated coefficients of $\beta$ for the covariates in all models indicate a direct association between the covariates and macaw occupation. Distance-tovillage is also included in the top models for the blue-andyellow and red-and-green macaws (Table 3). Occupation by blue-throated macaws also showed an association with historical occupation.

Mean constant detection probabilities of top models were $0.86 \pm$ SE 0.09 for blue-throated, $0.64 \pm$ SE 0.08 for blue-and-yellow, and $0.48 \pm \mathrm{SE} 0.13$ for red-and-green macaws. Detection probability was not associated with the
TABLE 2 Mean \pm SE of continuous covariates used to model the occupancy of large macaws in surveyed hexagons in the Beni savannahs, Bolivia (Fig. 1).

\begin{tabular}{ll}
\hline Covariate (unit) & Mean \pm SE (range) \\
\hline $\begin{array}{l}\text { Distance to the nearest village }(\mathrm{km}) \\
\text { Richness of cavity-nesters (species) }\end{array}$ & $38.4 \pm 4.9(0-92)$ \\
$\begin{array}{l}\text { Sum of the max. no. of blue-and-yellow \& } \\
\text { red-and-green macaws (individuals) }\end{array}$ & $6.5 \pm 2.5(0-71)$ \\
$\begin{array}{l}\text { Sum of the max. no. of blue-throated \& } \\
\text { blue-and-yellow macaws (individuals) }\end{array}$ & $6.2 \pm 2.2(0-56)$ \\
$\begin{array}{l}\text { Sum of the max. no. of blue-throated \& red- } \\
\text { and-green macaws (individuals) }\end{array}$ & $2.0 \pm 0.7(0-15)$ \\
$\begin{array}{l}\text { Duration of visit (hour) } \\
\text { num }\end{array}$ & $2.4 \pm 0.4(0.1-13.5)$ \\
\hline
\end{tabular}

duration of surveys for any of the species. In the models ranked above the model that assumes constant occupancy and detection probabilities across sites and surveys (i.e. $\Psi($.) $p()$.$) the goodness-of-fit test was not significant (\hat{c}<2$, Table 3), which suggests the model provides an adequate description of the data. In all top-ranked models $\psi$ confidence intervals included the naive estimation of occupancy.

We estimated conditional occupancy probabilities using the top-ranked model for each species (Fig. 2). Twenty of 29 hexagons surveyed showed a probability of occupancy by macaws of $>0.2$. We observed a greater spatial continuity in the distribution of blue-and-yellow and red-and-green macaws compared to the conditional occupancy probabilities of blue-throated macaws.

The blue-throated macaw was always associated with another species. In hexagons occupied by blue-throated macaws we used the probabilities of detection to estimate the number of macaws. We found a relationship of 5.4:1 between numbers of blue-and-yellow and blue-throated macaws detected and a relationship of $1.8: 1$ between numbers of red-and-green and blue-throated macaws detected.

\section{Discussion}

Macaws occupied two thirds of the surveyed hexagons and the blue-and-yellow macaw was the most common of the large macaws. The blue-throated macaw occupies small isolated areas and its distribution has not changed since 2000 (Hesse \& Duffield, 2000). Furthermore, the number of blue-throated macaws recorded (29 individuals) was in the range reported by the census conducted during 1993-1998 in the same area (Hesse \& Duffield, 2000). In all hexagons occupied by blue-throated macaws there was a high probability of occupancy of both blue-and-yellow and red-and-green macaws. Our results agree with previous records of joint presence of blue-throated and blue-and- 
TABLE 3 Top occupancy models and coefficients of covariates for blue-throated, blue-and-yellow, and red-and-green macaws in the Beni savannahs, Bolivia (Fig. 1).

\begin{tabular}{|c|c|c|c|c|c|c|c|c|c|c|c|c|}
\hline \multirow[b]{2}{*}{ Models $^{1}$} & \multirow[b]{2}{*}{$\Delta \mathrm{AICc}^{2}$} & \multirow[b]{2}{*}{$w^{3}$} & \multirow[b]{2}{*}{$k^{4}$} & \multirow[b]{2}{*}{-2 Log Like } & \multirow[b]{2}{*}{$\hat{\Psi}($ confidence interval $)$} & \multirow[b]{2}{*}{$\hat{c} \hat{c}$} & \multirow[b]{2}{*}{$\mathrm{p}$} & \multicolumn{5}{|c|}{ Occupancy parameters (mean \pm SE) } \\
\hline & & & & & & & & Intercept & $M$ & $D$ & $R$ & $H$ \\
\hline \multicolumn{13}{|c|}{$\begin{array}{l}\text { Blue-throated macaw } \\
\text { nach }\end{array}$} \\
\hline Naïve estimate $^{5}$ & & & & & 0.24 & & & & & & & \\
\hline$\Psi(M) p()$. & 0.00 & 0.88 & 3 & 19.32 & $0.24(0.11-0.38)$ & 0.86 & 0.48 & $-6.29 \pm$ SE 3.18 & $64.52 \pm$ SE 37.09 & & & \\
\hline$\Psi(H+R) p()$. & 5.48 & 0.06 & 4 & 22.09 & $0.25(0.12-0.39)$ & 0.92 & 0.47 & $-11.14 \pm$ SE 5.46 & & & $18.24 \pm$ SE 10.69 & $2.68(1.73)$ \\
\hline$\Psi(R) p()$. & 5.47 & 0.06 & 3 & 24.79 & $0.26(0.14-0.40)$ & 0.82 & 0.52 & $-11.16 \pm$ SE 6.04 & & & $20.76 \pm$ SE 12.51 & \\
\hline$\Psi(H) p()$. & 13.20 & 0.00 & 3 & 32.52 & $0.26(0.17-0.35)$ & 0.60 & 0.62 & $-2.85 \pm$ SE 1.03 & & & & $3.36(1.24)$ \\
\hline$\Psi() p.()$. & 21.51 & 0.00 & 2 & 43.33 & $0.25(0.12-0.44)$ & 0.81 & 0.51 & $-1.94 \pm$ SE 0.44 & & & & \\
\hline \multicolumn{13}{|c|}{ Blue-and-yellow macaw } \\
\hline Naïve estimate ${ }^{5}$ & & & & & 0.59 & & & & & & & \\
\hline$\Psi(D+R) p()$. & 0.00 & 0.39 & 4 & 77.93 & $0.63(0.50-0.73)$ & 1.43 & 0.22 & $-5.29 \pm$ SE 2.23 & & $3.95 \pm$ SE 2.41 & $12.03 \pm$ SE 5.24 & \\
\hline$\Psi(R) p()$. & 0.16 & 0.36 & 3 & 80.80 & $0.61(0.49-0.72)$ & 1.39 & 0.21 & $-3.90 \pm$ SE 1.86 & & & $11.53 \pm$ SE 4.91 & \\
\hline$\Psi(D) p()$. & 1.24 & 0.21 & 3 & 81.88 & $0.77(0.64-0.89)$ & 1.54 & 0.09 & $-3.59 \pm$ SE 2.53 & & $24.89 \pm$ SE 17.63 & & \\
\hline$\Psi(M) p()$. & 5.20 & 0.03 & 3 & 85.84 & $0.66(0.58-0.76)$ & 1.31 & 0.22 & $-0.04 \pm$ SE 0.53 & $17.82 \pm$ SE 15.18 & & & \\
\hline$\Psi() p.()$. & 9.13 & 0.00 & 2 & 92.27 & $0.67(0.44-0.84)$ & 1.23 & 0.20 & $0.71 \pm$ SE 0.48 & & & & \\
\hline \multicolumn{13}{|c|}{ Red-and-green macaw } \\
\hline Naïve estimate $^{5}$ & & & & & 0.34 & & & & & & & \\
\hline$\Psi(R) p()$. & 0.00 & 0.44 & 3 & 51.00 & $0.41(0.30-0.52)$ & 1.16 & 0.29 & $-5.04 \pm$ SE 2.3 & & & $10.85 \pm$ SE 5.3 & \\
\hline$\Psi(D+R) p()$. & 0.74 & 0.31 & 4 & 49.03 & $0.46(0.32-0.60)$ & 0.82 & 0.59 & $-9.05 \pm$ SE 4.71 & & $7.09 \pm$ SE 4.77 & $14.28 \pm$ SE 7.99 & \\
\hline$\Psi(M) p()$. & 1.59 & 0.20 & 3 & 52.59 & $0.41(0.31-0.51)$ & 1.09 & 0.35 & $-1.41 \pm$ SE 0.68 & $12.68 \pm$ SE 6.75 & & & \\
\hline$\Psi(D) p()$. & 4.58 & 0.04 & 3 & 55.58 & $0.53(0.42-0.64)$ & 0.68 & 0.78 & $-2.19 \pm$ SE 1.16 & & $5.81 \pm$ SE 2.91 & & \\
\hline$\Psi() p.()$. & 8.12 & 0.00 & 2 & 61.62 & $0.49(0.19-0.79)$ & 1.04 & 0.40 & $-0.04 \pm$ SE 0.70 & & & & \\
\hline
\end{tabular}

${ }^{1}$ Covariates: $M$, maximum number of individuals of other macaw species; $D$, distance to the nearest village; $R$, richness of cavity-nesting species; $H$, historical occupation by the blue-throated macaw

${ }^{2}$ Differences in $\mathrm{AIC}_{\mathrm{c}}$ value relative to the top model

${ }^{3} \mathrm{AIC}_{\mathrm{c}}$ weight

${ }^{4}$ Number of parameters in the model

${ }^{5}$ Proportion of sampling units where the species was detected 


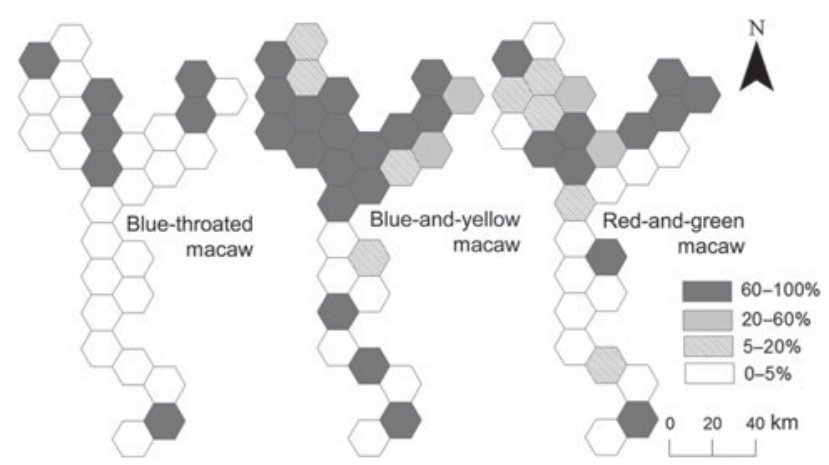

FIG. 2 Maps of conditional occupancy probability for the bluethroated Ara glaucogularis, blue-and-yellow Ara ararauna and red-and-green macaws Ara chloropterus in the Beni savannahs, Bolivia (Fig. 1). The conditional occupancy probabilities were estimated by the best-ranked model for each species.

yellow macaws (Jordan \& Munn, 1993; Yamashita \& de Barros, 1997; Herrera et al., 2007).

Considering the whole area the blue-and-yellow macaw was the most abundant species, outnumbering the red-andgreen macaw by $3.5: 1$ and the blue-throated macaw by $8.4: 1$. Blue-and-yellow macaws outnumbered blue-throated macaws at a lower ratio than the $20: 1$ reported by Jordan \& Munn (1993).

This is the first time that probabilities of detection have been modelled for macaws. We found similar naïve and modelled probabilities of detection for each species. Detection probability was not associated with sampling effort (i.e. with the duration of the surveys). Differences in detection probabilities between species may be associated with flock size and density. Blue-and-yellow macaws, which usually move in larger flocks, showed a higher probability of detection than red-and-green macaws, which are usually found in pairs. The high detection probability of the bluethroated macaw may be a consequence of its tendency to occur together with other macaw species, in areas with higher macaw density. These and other variables should be investigated to determine how they affect detection probability.

Palm tree species and cattle were distributed widely throughout our sampling grid, whereas macaws occupied smaller fractions of the surveyed area. At the landscape scale we were unable to explore whether palm species are reliable indicators of macaw presence. Studies of habitat use at smaller scales may be needed to examine suggested associations between palms and macaws (e.g. A. phalerata and the blue-throated macaw; Hesse \& Duffield, 2000).

The positive effect of cavity-nester species richness and abundance of other large macaw species on the occupancy of the three species studied here suggests a positive conservation status of occupied sites and a high availability of resources for macaws. This positive relationship is congruent with the general assumption that macaws require relatively pristine habitats (Forshaw, 1989) and suggests that macaws may be good biological indicators of forest conservation status.

The effect of distance-to-village on macaw occupancy has been used as a valid indirect measure of anthropogenic effects on wild animal populations in several studies (Arroyo-Rodríguez et al., 2008; Margalida et al., 2008). We found a positive association between distance-to-village and occupancy for the blue-and-yellow and red-and-green macaws; thus, these species could be experiencing higher pressure from hunters. Alternatively, this may be associated with low availability of resources near populated areas. In the case of the blue-throated macaw the absence of a clear effect of distance-to-village could be related to the low number of occupied sites, which may decrease statistical power for detection of a significant effect.

Based on our modelling blue-throated macaw occupancy was best predicted by the maximum number of other macaws detected, whereas blue-and-yellow and red-andgreen macaw occupancy were best predicted by distance-tovillage and cavity-nester richness. For red-and-green and blue-and-yellow macaws the Akaike differences between the first three models were not significant $(\triangle \mathrm{AICc}<2)$.

Apparently the range of the blue-throated macaw is not expanding, as suggested by the significant association between its occupancy and its historical occupation. We only detected blue-throated macaws in seven of the 11 hexagons occupied historically. Surveys conducted during 1992-1998 did not report a probability of detection for the blue-throated macaw (Jordan \& Munn, 1993; Yamashita \& de Barros, 1997; Hesse \& Duffield, 2000) and the number of individuals we detected (29) is similar to the numbers reported by those surveys. If we assume a similar probability of detection for all known surveys, there has not been a significant change in population size. Contrary to predictions based on population viability analysis (Strem \& Bouzat, 2012) the blue-throated macaw population may not be declining, which is a positive result for conservation, but abundance may not be increasing.

Conditional occupancy probability maps allowed us to identify key areas of importance for the blue-throated macaw and the other two macaw species. An efficient and informative monitoring scheme is needed to design and evaluate conservation initiatives aimed at securing the future of these species, and occupancy methods provide an efficient monitoring tool. The high detectability of macaw species allowed us to estimate occupancy from a low number of visits per sampling site. We consider that the shape and size of our sampling unit $\left(232.7 \mathrm{~km}^{2}\right)$ are appropriate for modelling occupancy of macaws at the landscape level and we recommend this sampling unit for future monitoring initiatives. Three visits to each unit was a sufficient sampling effort. The use of covariates, such as distance to nearest village and richness of cavity-nesting 
species, allowed us to predict the distribution range of macaw species. We believe that an efficient monitoring protocol could be achieved at a relatively low cost over a large number of sites in the Beni savannahs. Management institutions in developing countries where the monitoring of threatened parrot populations requires innovative approaches could implement similar monitoring protocols, which require a low level of training and expertise, and PRESENCE, required for the analyses, is freely available.

\section{Acknowledgements}

We thank P. Alvarez, F. Ávila, J. Casto Perez, C. Cuaino, V. Cuaino, C. Durán, J. Durán, R. Fernandez, L. González, H. Hoyos, R. Ibañez, J.C. Lisboa, A. Nacif, J. Nacif, I. Natusch, H. Parada, J. Rivero, A. Roca, E. Román, F. Román, J. Román, T. Salas, W. Villavicencio, P. Zabala, and R. Zabala for allowing us to work on their properties, and D. Añes, N. Franco, L. Gonzalez, M. Herrera and A.E. Rafael for their kind help and suggestions during fieldwork. This work was supported by The World Parrot Trust, Consejo Nacional de Investigaciones Científicas y Tecnológicas (CONICET PIP 112-20110-00358), ANPCyT (PICT 2011-0173), Universidad Nacional de La Plata (11/ n572, 1/n702) and Universidad Nacional del Centro de la Provincia de Buenos Aires, Rufford Small Grants Foundation, IdeaWild, Birder's Exchange, and CREOI.

\section{References}

Arroyo-Rodriguez, V., Mandujano, S. \& Benítez-Malvido, J. (2008) Landscape attributes affecting patch occupancy by howler monkeys (Alouatta palliata mexicana) at Los Tuxtlas, Mexico. American Journal of Primatology, 70, 69-77.

Beck, S.G. \& Moraes, M. (1997) Llanos de Mojos region, Bolivia. In Centres of Plant Diversity. Volume 3: The Americas (eds S.D. Davis \& V.H. Heywood), pp. 27-75. WWF/IUCN, Oxford, UK.

Berkunsky, I. (2008) Beginner's luck. PsittaScene, 20, 3-6.

Berkunsky, I. (2010) Mother of invention. PsittaScene, 22, 2-5.

Birdifife International (2013) Blue-throated macaw Ara glaucogularis. Http://www.birdlife.org/datazone/speciesfactsheet. php?id=1548 [accessed 14 November 2013].

Boussekey, M., Morvan, O. \& Saint-Pie, J. (1997) Preliminary observation of the blue-throated macaw Ara glaucogularis in the department of Beni (Bolivia). Papageienkunde, 1, 151-156.

Brightsmith, D. \& Bravo, A. (2006) Ecology and management of nesting blue-and-yellow macaws (Ara ararauna) in Mauritia palm swamps. Biodiversity and Conservation, 15, 4271-4287.

Brightsmith, D.J. \& Villalobos, E.M. (2011) Parrot behavior at a Peruvian clay lick. The Wilson Journal of Ornithology, 123, 595-602.

Cornelius, C., Cockle, K., Politi, N., Berkunsky, I., SandovalVARgAs, L., OJEDA, V. et al. (2008) Cavity-nesting birds in neotropical forests: cavities as a potentially limiting resource. Ornitologia Neotropical, 19, 253-268.

Duffield, G.E. \& Hesse, A.J. (1997) Ecology and conservation of the blue-throated macaw. PsittaScene, 9, 10-11.
Forshaw, J.M. (1989) Parrots of the World. Lansdowne Press, Willoughby, Australia.

Franchin, A.G. (2009) Avifauna em áreas urbanas brasileiras, com ênfase em cidades do Triângulo Mineiro/Alto Paranaíba. $\mathrm{PhD}$ thesis. Universidade Federal de Uberlândia, Brazil.

Gonzalez, J.A. (2003) Harvesting, local trade, and conservation of parrots in the Northeastern Peruvian Amazon. Biological Conservation, 114, 437-446.

Hanagarth, W. \& Beck, S.G. (1996) Biogeographie der Beni-Savannen (Bolivien). Geographische Rundschau, 48, 662-668.

Herrera, M., Vargas, H., Sandoval, V., Perskin, T. \& Rendón, O. (2007) Nuevo dato en la distribución de la Paraba barba azul (Ara glaucogularis). Kempffiana, 3, 18-24.

Hesse, A.J. \& Duffield, G.E. (2000) The status and conservation of the blue-throated macaw Ara glaucogularis. Bird Conservation International, 10, 255-275.

Ingels, J., Parkes, K.C. \& Farrand, JR, J. (1981) The status of the macaw generally but incorrectly called Ara caninde (Wagler). Le Gerfaut, 71, 283-294.

Jordan, O.C. \& Munn, C.A. (1993) First observations of the blue-throated macaw in Bolivia. Wilson Bulletin, 105, 694-695.

Juniper, T. \& PArr, M. (1998) Parrots: A Guide to the Parrots of the World. Yale University Press, New Haven, USA.

Karubian, J., Fabara, J., Yunes, D., Jorgenson, J.P., Romo, D. \& SMith, T.B. (2005) Temporal and spatial patterns of macaw abundance in the Ecuadorian Amazon. The Condor, 107, 617-626.

Kroll, A.J., Duke, S.D., Runde, D.E., Arnett, E.B. \& Austin, K.A. (2007) Modeling habitat occupancy of orange-crowned warblers in managed forests of Oregon and Washington, USA. The Journal of Wildlife Management, 71, 1089-1097.

LeE, A.T.K. \& MARsDen, S.J. (2012) The influence of habitat, season, and detectability on abundance estimates across an Amazonian parrot assemblage. Biotropica, 44, 537-544.

MacKenzie, D.I. \& Bailey, L.L. (2004) Assessing the fit of site-occupancy models. Journal of Agricultural, Biological and Environmental Statistics, 9, 300-318.

MacKenzie, D.I., Nichols, J.D., Royle, J.A., Pollock, K.H., BAiley, L.L. \& Hines, J.E. (2005) Occupancy Estimation and Modeling: Inferring Patterns and Dynamics of Species Occurrence. Elsevier Academic Press, Burlington, USA.

Margalida, A., Donázar, J.A., Bustamante, J., Hernández, F.J. \& Romero-Pujante, M. (2008) Application of a predictive model to detect long-term changes in nest-site selection in the bearded vulture Gypaetus barbatus: conservation in relation to territory shrinkage. Ibis, 150, 242-249.

Mayle, F.E., Langstroth, R.P., Fisher, R.A. \& Meir, P. (2007) Long-term forest-savannah dynamics in the Bolivian Amazon: implications for conservation. Philosophical Transactions of the Royal Society B: Biological Sciences, 362, 291-307.

Olea, P.P. \& MATEO-Tomás, P. (2011) Spatially explicit estimation of occupancy, detection probability and survey effort needed to inform conservation planning. Diversity and Distributions, 17, 714-724.

Renton, K. \& Brightsmith, D.J. (2009) Cavity use and reproductive success of nesting macaws in lowland forest of southeast Peru. Journal of Field Ornithology, 80, 1-8.

Roberge, J.-M. \& Angelstam, P. (2006) Indicator species among resident forest birds-A cross-regional evaluation in northern Europe. Biological Conservation, 130, 134-147.

Roth, P. (1984) Repartição do habitat entre psitacídeos simpátricos no Sul da Amazônia. Acta Amazônica, 14, 175-221.

Snyder, N., McGowan, P., Gilardi, J.D. \& Grajal, A. (eds) (2000) Parrots: Status Survey and Conservation Action Plan 2000-2004. IUCN, Gland, Switzerland, and Cambridge, UK. 
Strem, R.I. \& Bouzat, J.L. (2012) Population viability analysis of the blue-throated macaw (Ara glaucogularis) using individual-based and cohort-based PVA programs. The Open Conservation Biology Journal, 6, 12-24.

WELLER, T.J. (2008) Using occupancy estimation to assess the effectiveness of a regional multiple-species conservation plan: bats in the Pacific Northwest. Biological Conservation, 141, 2279-2289.

Yamashita, C. \& De Barros, Y.M. (1997) The blue-throated macaw Ara glaucogularis: characterization of its distinctive habitats in savannahs of the Beni, Bolivia. Ararajuba, 5, 141-150.

Zeller, K.A., Nijhawan, S., Salom-Pérez, R., Potosme, S.H. \& Hines, J.E. (2011) Integrating occupancy modeling and interview data for corridor identification: a case study for jaguars in Nicaragua. Biological Conservation, 144, 892-901.

\section{Biographical sketches}

IGOR BERKUNSKY'S primary research interests are the conservation biology of relict and endemic organisms. Rosana CEPEDA, Claudia Marinelli and Verónica Simoy are a statistics and mathematics team with many years of experience working in modelling and multivariate analysis. Gonzalo Daniele and FACUNDO GANDOY are experienced bird surveyors with an interest in conservation. FEDERICO KACOLIRIS is interested in conservation biology, protected areas and herpetology. José Díaz LUQUE studies parrots and macaws in Bolivian lowlands, and leads parrot conservation projects in the Neotropics. RosanA ARAMBURÚ's research is focused on Neotropical species of parrots. JAMES Gilardi is interested in the ecology and conservation of parrots. 